\title{
Ti3C2Tx MXene Quantum Dots with Enhanced Stability for Ultrafast Photonics
}

Yang, Fumei; Ge, Yanqi; Yin, Teng; Guo, Jia; Zhang, Feng; Tang, Xian; Qiu, Meng; Liang, Weiyuan; Xu, Ning; Wang, Cong

Total number of authors:

13

Published in:

ACS Applied Nano Materials

Link to article, DOI:

10.1021/acsanm.0c02369

Publication date:

2021

Document Version

Peer reviewed version

Link back to DTU Orbit

Citation (APA):

Yang, F., Ge, Y., Yin, T., Guo, J., Zhang, F., Tang, X., Qiu, M., Liang, W., Xu, N., Wang, C., Song, Y., Xu, S., \& Xiao, S. (2021). Ti C T MXene Quantum Dots with Enhanced Stability for Ulltrafast Photonics. ACS Applied

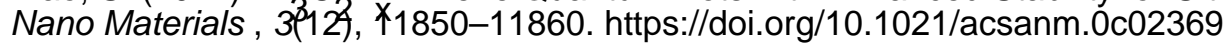

\section{General rights}

Copyright and moral rights for the publications made accessible in the public portal are retained by the authors and/or other copyright owners and it is a condition of accessing publications that users recognise and abide by the legal requirements associated with these rights.

- Users may download and print one copy of any publication from the public portal for the purpose of private study or research.

- You may not further distribute the material or use it for any profit-making activity or commercial gain

- You may freely distribute the URL identifying the publication in the public portal 


\title{
$\mathrm{Ti}_{3} \mathrm{C}_{2} \mathrm{~T}_{x}$ MXene Quantum Dots with Enhanced Stability for Ultrafast Photonics
}

\author{
Fumei Yang, ${ }^{\ddagger}$ Yanqi Ge, ${ }^{+}$Teng Yin,, Jia Guo, Feng Zhang, Xian Tang, Meng Qiu, Weiyuan Liang, \\ $\mathrm{Ning} \mathrm{Xu}$, Cong Wang, Yufeng Song, Shixiang $\mathrm{Xu}, *$ and Sanshui Xiao*
}

Cite This: https://dx.doi.org/10.1021/acsanm.0c02369

Read Online

ACCESS | Llll Metrics \& More | 回 Article Recommendations

(s) Supporting Information

ABSTRACT: MXenes, as an emerging group of two-dimensional materials, have attracted significant interest for diverse photoelectric applications by virtue of their tunable terminated surface, excellent electrical conductivity, and strong nonlinear optical response. They are usually synthesized via strategies involving hydrofluoric acid, which may result in oxygenic and hydrophilic termination groups on the MXene surface and thus decrease their stability in air. Herein, a mild synthesis method based on electrochemical exfoliation is proposed to prepare $\mathrm{Ti}_{3} \mathrm{C}_{2} \mathrm{~T}_{x}$ MXene quantum dots (QDs), which are highly fluorinated to enhance stability. The open-aperture Z-scan system was employed to measure the nonlinear transmittance of the MXene QDs and proves their broadband saturable

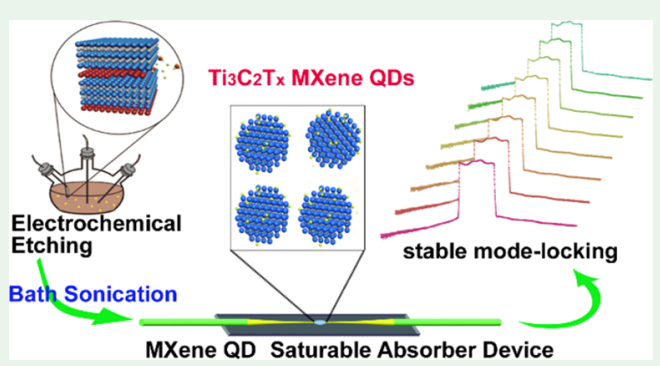
absorption from 540 to $1550 \mathrm{~nm}$. By integrating the MXene QD saturable absorber into an ytterbium-doped fiber laser, a set of highly stable 357 ps mode-locked pulses centered at $1069.17 \mathrm{~nm}$ was achieved under a low threshold power of $54 \mathrm{~mW}$. In addition, tunable mode-locked optical spectra could be observed in the cavity when switching the polarization state. This work provides an environmentally friendly approach to synthesize stable MXene QDs and opens an avenue for the realization of low-threshold and tunable photonics applications based on MXene QDs.

KEYWORDS: $\mathrm{Ti}_{3} \mathrm{C}_{2} \mathrm{~T}_{x}$ MXene quantum dots, nonlinear optical properties, saturable absorbers, mode-locked fiber laser, pulsed laser generation, fluorination

\section{INTRODUCTION}

A novel family of two-dimensional (2D) transition metal carbides, nitrides, and carbon nitrides (MXenes) was first realized by Gogotsi et al. in $2011^{1}$ and has recently gained marked interest because of the promising prospects for advanced applications. The structural formula of MXene could be expressed as $\mathrm{M}_{n+1} \mathrm{X}_{n} \mathrm{~T}_{x}(n=1,2,3)$, where $\mathrm{M}$ stands for an early transition metal, $\mathrm{X}$ for carbon and/or nitrogen, and $\mathrm{T}_{x}$ for the surface terminated functional group. ${ }^{2}$ They exhibit high metallic conductivities, ${ }^{3,4}$ good mechanical performance, ${ }^{5}$ strong nonlinear optical response, ${ }^{6}$ and excellent thermoelectric properties, ${ }^{7}$ which allow for wide functionality in various applications, including in energy storage, ${ }^{2,8}$ biosensors, ${ }^{9,10}$ catalysis, ${ }^{11,12}$ and ultrafast lasers. ${ }^{13,14}$ As for MXene quantum dots (QDs), they feature intriguing optoelectronic properties, fluorescence behavior, and photothermal conversion by virtue of the quantum confinement and edge effects in addition to inheriting the merit of their 2D counterparts. $^{15}$ Several effective functionalization methods are performed to enhance their properties, including surface modification, ${ }^{16}$ heteroatom doping, ${ }^{17}$ and constructing composites, $^{18}$ rendering them to practical applications, such as sensors, optoelectronics, and energy storage. ${ }^{15}$

In particular, functional groups may be terminated on the surface of MXene, allowing for enhanced stability and superior properties. ${ }^{19}$ Generally, layered MAX phases are exfoliated by hydrofluoric acid (HF) etching. The use of high concentrations of HF results in issues related to toxicity, environmental pollution, and the formation of numerous defects on the MXene surface. ${ }^{1,20,21}$ Furthermore, MXene obtained from HF-assisted synthesis is usually contaminated with oxygenic and hydrophilic termination groups, such as $-\mathrm{O}$ and $-\mathrm{OH}$, resulting in deterioration of the stability of the MXene material. $^{22}$ To cope with these issues, many alternative etchants have been explored to substitute for HF. One is the use of $\mathrm{HCl}$ and $\mathrm{LiF} / \mathrm{NaF}$ to in situ generate $\mathrm{HF}$ to realize selective etching. ${ }^{23}$ Another is molten fluorides that can synthesize MXene in high temperature. ${ }^{24,25}$ Recently, more synthesis methods have been used to avoid using HF, such as a CVD method, ${ }^{26}$ powerful probe sonication, ${ }^{16}$ alkali treatment, ${ }^{27}$ and electrochemical exfoliation. ${ }^{28}$ However, the aqueous and alkaline condition generally leads to tremendous oxygenic and hydrophilic groups on the surfaces, which may

Received: September 1, 2020

Accepted: November 11, 2020 
contribute to the fast degradation of the MXene. According to our experience, the use of the $\mathrm{F}^{-}$group can improve the stability of the 2D materials because of fluorine adatominduced blocking of the charge transfer pathway from the MXene surface to the external oxygen. ${ }^{29}$ Inspired by the conclusions in ref 21 , we proposed an electrochemical exfoliation strategy with synchronous fluorination to synthesize MXene $\mathrm{Ti}_{3} \mathrm{C}_{2} \mathrm{~T}_{x}$ quantum dots. In this process, a non-aqueous and mild ionic liquid was employed as the electrolyte; toxic HF could be avoided, and the MXene QDs were effectively fluorinated.

Recently, the nonlinear optical properties of MXene have been extensively explored because of their strong light-matter interaction. Jhon et al. explored the saturable absorption properties of metallic $\mathrm{Ti}_{3} \mathrm{CNT}_{x}$; they realized femtosecond pulse output and passive Q-switching ranging from 1500 to $2000 \mathrm{~nm}$, confirming that MXenes can serve as broadband saturable absorbers (SAs). ${ }^{14}$ Jiang et al. systematically studied the nonlinear optical response of $\mathrm{Ti}_{3} \mathrm{C}_{2} \mathrm{~T}_{x}$ from 800 to 1800 $\mathrm{nm}$ and realized stable mode-locking at both 1066 and 1555 $\mathrm{nm}$, suggesting the potential for advanced broadband photonic applications. ${ }^{13}$ These two works opened the door for the exploration of the nonlinear optical properties of the MXene family. Subsequently, different types of MXenes, including $\mathrm{Ti}_{3} \mathrm{C}_{2} \mathrm{~T}_{x}$ and $\mathrm{Ti}_{3} \mathrm{C}_{2}$, were demonstrated as efficient SAs for ultrafast applications in the visible to mid-infrared in fiber or bulk laser cavities. ${ }^{30-33}$ It was confirmed that MXene has the advantages of broadband response, high damage threshold, and adjustable saturation absorption parameters. However, these studies focused on few-layer MXene or MXene nanosheets and not on MXene QDs. One of the reasons is poor stability as the size of MXene becomes smaller than $600 \mathrm{~nm}$ (particularly MXene QDs), even though MXene itself has a relatively good oxidation resistance. ${ }^{22}$ The optical nonlinearities and photonic applications of MXene QDs have yet to be investigated, and the performance and long-term stability of smaller-size MXenes still face great challenges.

In this work, fluorinated $\mathrm{Ti}_{3} \mathrm{C}_{2} \mathrm{~T}_{x}$ QDs were synthesized via the electrochemical etching method, which is a convenient and environment-friendly synthetic method. The fluorinated MXene QDs exhibit strong absorption in the NIR region and enhanced stability under ambient conditions. Broadband saturable absorption from 540 to $1550 \mathrm{~nm}$ was observed via the open-aperture (OA) Z-scan technique. It is noteworthy that the saturable absorption intensity was found to be in the order of $10^{-3} \mathrm{GW} \mathrm{cm} \mathrm{cm}^{-2}$ (lowest at $1064 \mathrm{~nm}$ ), which is comparable with that of graphene, and this is beneficial for a lower mode-locking threshold in lasers. Fluorinated MXene QDs were deposited onto a microfiber as a saturable absorber device and incorporated into an ytterbium-doped fiber laser (YDFL). Highly stable mode-locked pulses centered at $1069.17 \mathrm{~nm}$ were obtained at a low threshold power of 54 $\mathrm{mW}$. Surprisingly, tunable optical spectra could be observed by fine-tuning the polarization controllers. This work demonstrates that fluorinated $\mathrm{Ti}_{3} \mathrm{C}_{2} \mathrm{~T}_{x}$ QDs with enhanced performance have excellent potential for application in low-threshold ultrafast photonics devices.

\section{RESULTS AND DISCUSSION}

2.1. Synthesis and Characterization of $\mathrm{Ti}_{3} \mathrm{C}_{2} \mathrm{~T}_{x} \mathrm{MXene}$ QDs. As Figure 1 shows, a three-electrode electrometrical system, including a working electrode, a quasi-reference

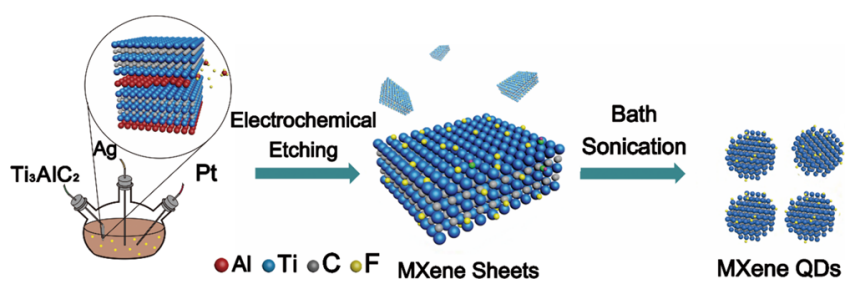

Figure 1. Schematic of the synthesis setup and the synthesis of the $\mathrm{Ti}_{3} \mathrm{C}_{2} \mathrm{~T}_{x}$ QDs.

electrode, and a counterelectrode, has been used to synthesize the $\mathrm{Ti}_{3} \mathrm{C}_{2} \mathrm{~T}_{x}$ MXene QDs.

The electrolyte consisted of non-aqueous ionic liquid 1butyl-3-methylimidazolium hexafluorophosphate ([BMIM]$\left.\left[\mathrm{PF}_{6}\right]\right)$ and cetonitrile $(\mathrm{MeCN})$. The electrochemical etching and fluorination mechanism of the $\mathrm{Ti}_{3} \mathrm{AlC}_{2}$ QDs is described in detail in the Supporting Information (Section S2). Because $\mathrm{F}^{-}$has a strong binding capability with $\mathrm{Al}$, fluorine-containing ionic liquids generally present clear etching effects. A constant potential versus the $\mathrm{Ag}$ wire was conducted on the working electrode to exfoliate the precursor $\mathrm{Ti}_{3} \mathrm{AlC}_{2}$. After $5 \mathrm{~h}$ of exfoliation, the process was finished with the current of the electrolyte being set to 0 . The resulting sediments in the electrolyte were removed from the exfoliation over several cycles of rinsing by $\mathrm{MeCN}$. The MXene QDs can be produced by ultrasonication under $\mathrm{N}_{2}$ from MXene particles and collected by centrifugation. Details of the experiment are given in the Experimental Section. Before synthesis, cyclic voltammetry $(\mathrm{CV})$ testing of an electrolyte with $1.0 \mathrm{M}$ $[\mathrm{BMIM}]\left[\mathrm{PF}_{6}\right]$ in $\mathrm{MeCN}$ was performed. The sample was added with a calibration sample of ferrocene $\left(2.0 \times 10^{-3} \mathrm{M}\right)$. The CV curve results are shown in Figure S1. The exfoliation potential for $\mathrm{Ti}_{3} \mathrm{AlC}_{2}$ can be obtained by reference to the oneelectron redox peaks in the $\mathrm{CV}$ test. The photothermalconversion performance and stability of the $\mathrm{Ti}_{3} \mathrm{C}_{2} \mathrm{~T}_{x}$ QDs over 15 days were also recorded, as shown in Figure S3, which indicated the improved stability of the fluorinated $\mathrm{Ti}_{3} \mathrm{C}_{2} \mathrm{~T}_{x}$ QDs compared with MXene QDs obtained via HF etching.

Transmission electron microscopy (TEM) was employed to analyze the structure and morphology of the as-synthesized MXene QDs. The TEM image of the as-prepared MXene QDs in Figure 2a reveals the uniform and ultra small MXene QDs. The high-resolution TEM (HRTEM) image in Figure 2b was further employed to examine the crystal structure of the QDs. As shown in Figure 2c, the lattice fringes had an inner plane spacing of $0.21 \mathrm{~nm}$, which corresponds with the (0110) facet of the $\mathrm{Ti}_{3} \mathrm{C}_{2}$ MXene. As shown in Figure $2 \mathrm{~d}$, the average lateral size was calculated as $\sim 5.34 \mathrm{~nm}$ via statistical TEM analysis of 100 MXene QDs. AFM analysis (Figure S2a) demonstrated that the thickness of the MXene QDs is around $4 \mathrm{~nm}$. According to the X-ray diffraction (XRD) results (Figure 2e), the diffraction peaks with the $2 \theta$ values at $9.5^{\circ}, 18^{\circ}, 28^{\circ}, 39.0^{\circ}$, and $41.8^{\circ}$ correspond to the (002), (004), (0008), (101), and (105) crystal planes of crystalline $\mathrm{Ti}_{3} \mathrm{AlC}_{2}$, respectively. ${ }^{34-36}$ After electrochemical etching, a broadened and amorphous signal at $\sim 24^{\circ}(2 \theta)$ was observed, which is similar to the MXene QDs synthesized via hydrothermal methods ${ }^{27}$ or delaminated few-layer MXene by HF etching. ${ }^{37}$ The obvious characteristic peak at $39^{\circ}$ for the $\mathrm{Ti}_{3} \mathrm{AlC}_{2}$ MAX was absent, indicating complete delamination of the $\mathrm{Ti}_{3} \mathrm{C}_{2} \mathrm{~T}_{x}$ MXene. ${ }^{28} \mathrm{To}$ investigate the absorption properties of the MXene QDs, the MXene QD solution was added to deionized water. The UV- 

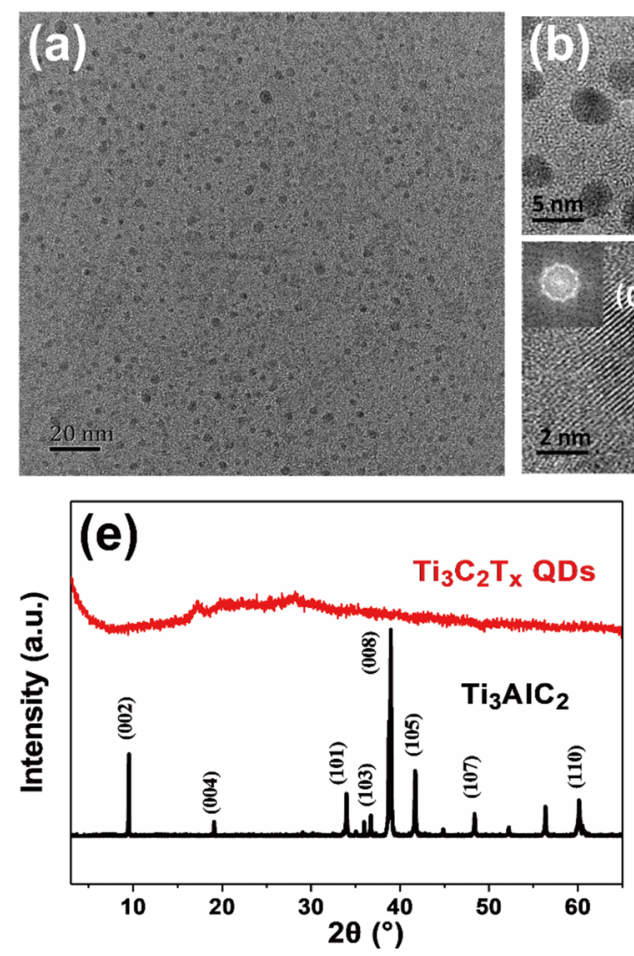
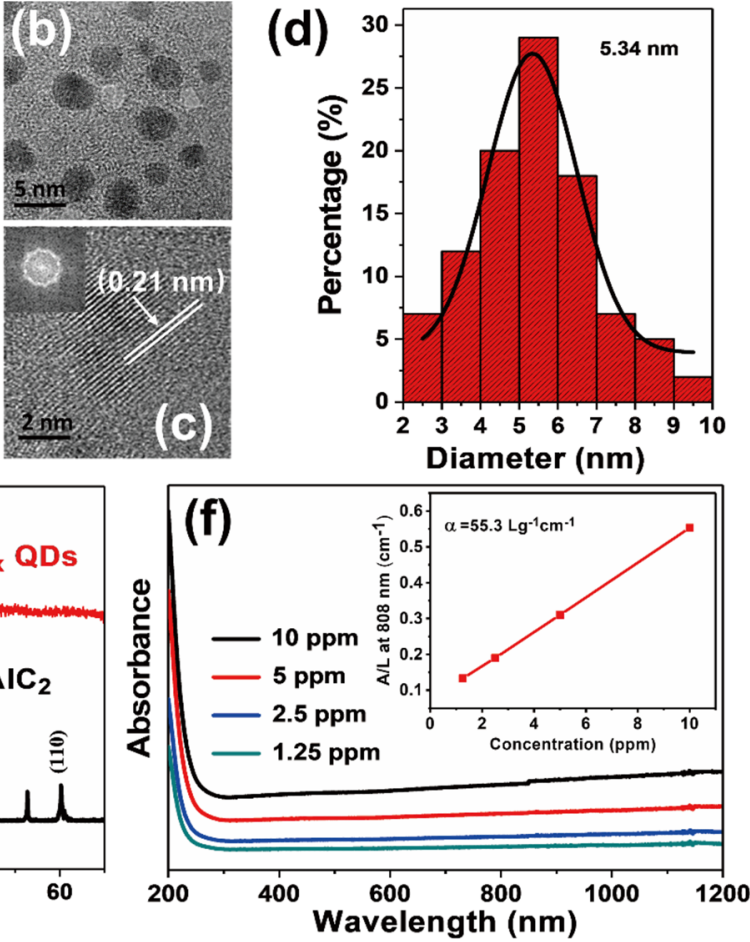

Figure 2. (a) TEM image of $\mathrm{Ti}_{3} \mathrm{C}_{2} \mathrm{~T}_{x}$ QDs. (b and c) HRTEM images of $\mathrm{Ti}_{3} \mathrm{C}_{2} \mathrm{~T}_{x}$ QDs. (d) Diameter distribution of $\mathrm{Ti}_{3} \mathrm{C}_{2} \mathrm{~T}_{x}$ QDs. (e) XRD pattern of the $\mathrm{Ti}_{3} \mathrm{AlC}_{2}$ powders and $\mathrm{Ti}_{3} \mathrm{C}_{2} \mathrm{~T}_{x}$ QDs. (f) Absorption spectra of MXene QDs with various concentrations. The insert of (f) is the normalized absorbance intensity at $\lambda=808 \mathrm{~nm}$.
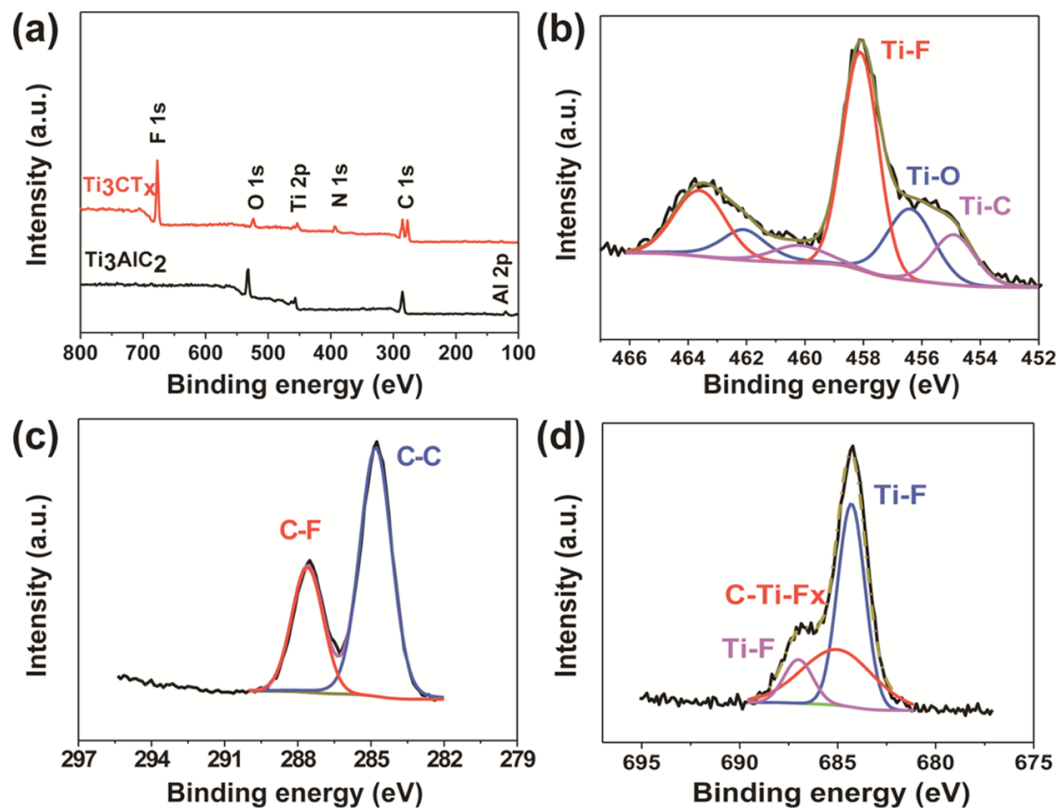

Figure 3. (a) X-ray photoelectron spectroscopy for $\mathrm{Ti}_{3} \mathrm{AlC}_{2}$ and $\mathrm{Ti}_{3} \mathrm{C}_{2}$. (b-d) High-resolution XPS of Ti 2p, C 1s, and F 1s, respectively.

Vis-NIR absorption spectra of the MXene QDs with different concentrations are shown in Figure 2f. The MXene QDs exhibited a broad absorption ranging from the UV to NIR region. This absorption characteristic of MXene QDs is similar to that of the few-layer MXene $\mathrm{Ti}_{3} \mathrm{C}_{2} \mathrm{~T}_{x}{ }^{13}$ The normalized absorption intensity over the length of the cell $(A / L)$ with different concentrations $(C)$ was examined at a wavelength of $808 \mathrm{~nm}$ (inset of Figure 2f). The extinction coefficient of the MXene QDs was determined by using the Lambert-Beer law $^{38}$

$$
A / L=\alpha \mathrm{C}
$$

where $A$ stands for the absorbance of the samples, $\alpha$ is the extinction coefficient, and $L$ represents the characteristic length of the cell. The extinction coefficient at $808 \mathrm{~nm}$ was measured as $55.3 \mathrm{~L} \mathrm{~g}^{-1} \mathrm{~cm}^{-1}$, which is much higher than that of the HFsynthesized $\mathrm{Ti}_{3} \mathrm{C}_{2} \mathrm{~T}_{x}$ nanosheets $\left(29.1 \mathrm{~L} \mathrm{~g}^{-1} \mathrm{~cm}^{-1}\right){ }^{39}$ According to the results, the MXene QDs exhibited a strong NIR absorption, which could contribute to some important optical applications. 
(a)

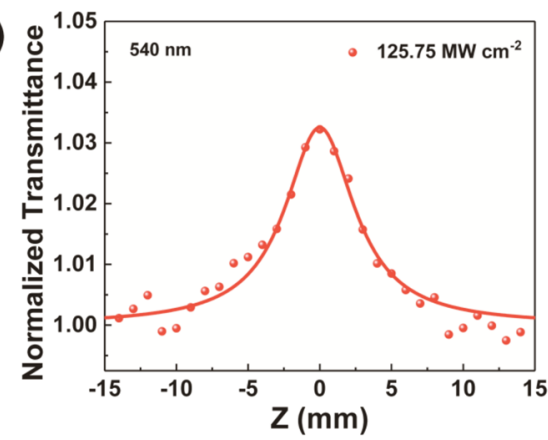

(c)

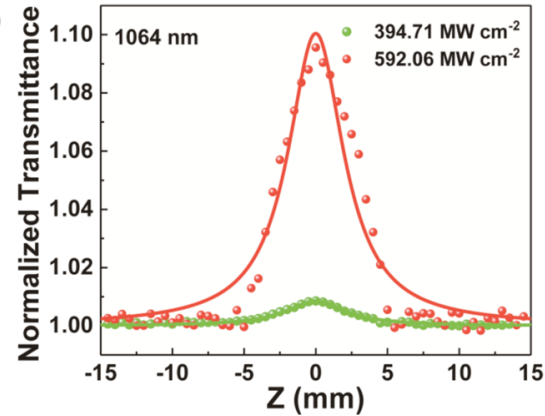

(b)

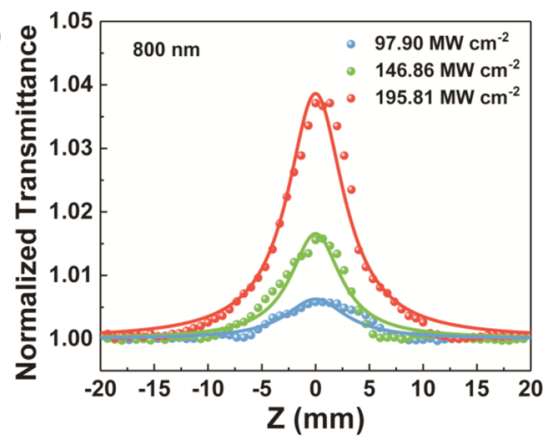

(d)

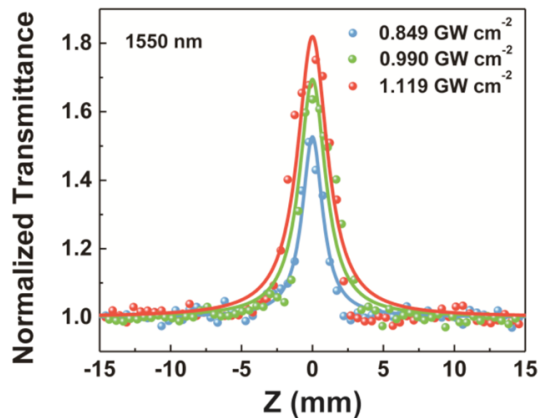

Figure 4. OA Z-scan results of fluorinated $\mathrm{Ti}_{3} \mathrm{C}_{2} \mathrm{~T}_{x}$ QDs at four wavelengths: (a) 540, (b) 800, (c) 1064, and (d) $1550 \mathrm{~nm}$.

Table 1. Comparison of the Nonlinearities among Different Mainstream 2D Materials

\begin{tabular}{|c|c|c|c|c|}
\hline 2D materials & wavelength $(\mathrm{nm})$ & $\alpha_{\mathrm{NL}}\left(\mathrm{cm} \mathrm{GW}{ }^{-1}\right)$ & $I_{\text {sat }}\left(\mathrm{MW} \mathrm{cm}^{-2}\right)$ & $\Delta T(\%)$ \\
\hline graphene $^{53}$ & 1550 & NA & $0.71-0.61$ & $66.5-6.2$ \\
\hline $\mathrm{MoS}_{2}^{50}$ & 800 & $-(4.60 \pm 0.27) \times 10^{-3}$ & $(413 \pm 24) \times 10^{-3}$ & NA \\
\hline $\mathrm{BP}^{51}$ & 800 & $-(4.08 \pm 0.11) \times 10^{-3}$ & $(647.7 \pm 60) \times 10^{-3}$ & 13.30 \\
\hline $\mathrm{BP} \mathrm{QDs}^{52}$ & 800 & $-(5.9 \pm 0.12) \times 10^{-3}$ & $3.3 \times 10^{-3}$ & 36 \\
\hline Se-doped BP nanosheets ${ }^{49}$ & 800 & $-8.8 \times 10^{-3}$ & $240 \times 10^{-3}$ & 18.7 \\
\hline MXene nanosheets $\mathrm{Ti}_{3} \mathrm{C}_{2} \mathrm{~T}_{x}{ }^{13}$ & 800 & -0.297 & $(88.6 \pm 5) \times 10^{-3}$ & NA \\
\hline MXene nanosheets $\mathrm{Ti}_{3} \mathrm{C}_{2} \mathrm{~T}_{x}{ }^{13}$ & 1064 & -0.206 & $(61.2 \pm 5) \times 10^{-3}$ & $38.3 \pm 2.0$ \\
\hline MXene nanosheets $\mathrm{Ti}_{3} \mathrm{C}_{2} \mathrm{~T}_{x}{ }^{13}$ & 1550 & -0.358 & $(39.1 \pm 5) \times 10^{-3}$ & NA \\
\hline $\mathrm{Ti}_{3} \mathrm{C}_{2} \mathrm{~T}_{x}$ QDs (this work) & 540 & -7.32 & $1.26 \pm 0.22$ & $2.94 \pm 0.10$ \\
\hline $\mathrm{Ti}_{3} \mathrm{C}_{2} \mathrm{~T}_{x}$ QDs (this work) & 800 & -5.58 & $1.10 \pm 0.04$ & $3.52 \pm 0.38$ \\
\hline $\mathrm{Ti}_{3} \mathrm{C}_{2} \mathrm{~T}_{x}$ QDs (this work) & 1064 & -4.80 & $0.216 \pm 0.03$ & $7.72 \pm 0.38$ \\
\hline $\mathrm{Ti}_{3} \mathrm{C}_{2} \mathrm{~T}_{x}$ QDs (this work) & 1550 & -22.04 & $1.55 \pm 0.257$ & $21.75 \pm 1.14$ \\
\hline
\end{tabular}

The X-ray photoelectron spectroscopy (XPS) results for the synthesized $\mathrm{Ti}_{3} \mathrm{C}_{2} \mathrm{~T}_{x}$ QDs are displayed in Figure 3. The appearance of the strong fluorine peak clearly indicated the formation of surface groups of $-\mathrm{F}$. The high-resolution XPS of aluminum inserted in Figure S4 shows the absence of the Al species after electrochemical exfoliation, confirming the complete exfoliation of the $\mathrm{Al}$ layer from $\mathrm{Ti}_{3} \mathrm{AlC}_{2}$. For Ti $2 \mathrm{p}$ spectra (Figure 3b), peak fitting at $459.9 \mathrm{eV}$ confirms the presence of $\mathrm{Ti}-\mathrm{C}(2 \mathrm{p} 3),{ }^{40}$ indicating that the $\mathrm{Ti}_{3} \mathrm{C}_{2}$ structure remained during the electrochemical exfoliation process. The strong peak centered at $458.0 \mathrm{eV}$ suggests the existence of Ti$\mathrm{F}(2 \mathrm{p} 3) .{ }^{41}$ The main peaks at 284.8 and $287.6 \mathrm{eV}$ in the $\mathrm{C} 1 \mathrm{~s}$ spectrum were ascribed to the $\mathrm{C}-\mathrm{C}$ and $\mathrm{C}-\mathrm{F}$ bonds, respectively (Figure $3 \mathrm{c}$ ). ${ }^{42}$ The binding energies of 686.8, 685.2 , and $684.4 \mathrm{eV}$ in the $\mathrm{F} 1 \mathrm{~s}$ spectra can be attributed to $\mathrm{F}-$ $\mathrm{C},{ }^{43} \mathrm{C}-\mathrm{Ti}-\mathrm{F}_{x}{ }^{44}$ and $\mathrm{F}-\mathrm{Ti}^{40}{ }^{40}$ which agrees well with the Ti $2 \mathrm{p}$ and $\mathrm{C} 1 \mathrm{~s}$ spectra. It can be seen that the $\mathrm{F}$ atoms bond with both $\mathrm{Ti}$ and $\mathrm{C}$ atoms. The strong $\mathrm{F} 1 \mathrm{~s}$ peak also indicates that the synthesized $\mathrm{Ti}_{3} \mathrm{C}_{2} \mathrm{~T}_{x}$ QDs were effectively terminated by - F. Fourier transform infrared (FTIR) spectroscopy (Figure S2c) was also performed to determine the chemical bonds of the fluorinated MXene QDs and HF-synthesized MXene nanosheets. The strong peak around $1100 \mathrm{~cm}^{-1}$ corresponds to the $\mathrm{C}-\mathrm{F}$ bond, and the peak at $751 \mathrm{~cm}^{-1}$ corresponds to the $\mathrm{Ti}-\mathrm{F}$ bond. ${ }^{45,46}$ The intensive $\mathrm{C}=\mathrm{O}$ bond $\left(1650 \mathrm{~cm}^{-1}\right)$ only appeared in the HF-synthesized MXene nanosheets. ${ }^{46}$ The peak at $636 \mathrm{~cm}^{-1}$ corresponds to the vibration of $\mathrm{Ti}-\mathrm{O},{ }^{46}$ which agrees well with the XPS results. These observations further prove that $\mathrm{Ti}_{3} \mathrm{C}_{2} \mathrm{~T}_{x}$ QDs were highly fluorinated during the electrochemical exfoliation process.

2.2. Nonlinear Absorption Characterization of Fluorinated $\mathrm{Ti}_{3} \mathrm{C}_{2} \mathrm{~T}_{x}$ QDs. To investigate the broadband nonlinear absorption properties of the fluorinated $\mathrm{Ti}_{3} \mathrm{C}_{2} \mathrm{~T}_{x} \mathrm{QDs}$, an $\mathrm{OA}$ Z-scan technique ${ }^{47}$ was performed using femtosecond lasers with four wavelengths centered at 540,800, 1060, and 1550 $\mathrm{nm}$. The experimental setup has been well described in our previous work, ${ }^{48}$ and the details of the Z-scan system are described in the Experimental Section.

First, a pure $\mathrm{MeCN}$ solution in a cuvette was tested under the OA Z-scan system; only a featureless curve was obtained, enabling us to exclude any influence originating from the $\mathrm{MeCN}$ solution and cuvette. Figure 4 shows the experimental measurement of the fluorinated $\mathrm{Ti}_{3} \mathrm{C}_{2} \mathrm{~T}_{x}$ QDs after the Z-scan process at different wavelengths. The fluorinated $\mathrm{Ti}_{3} \mathrm{C}_{2} \mathrm{~T}_{x} \mathrm{QDs}$ 

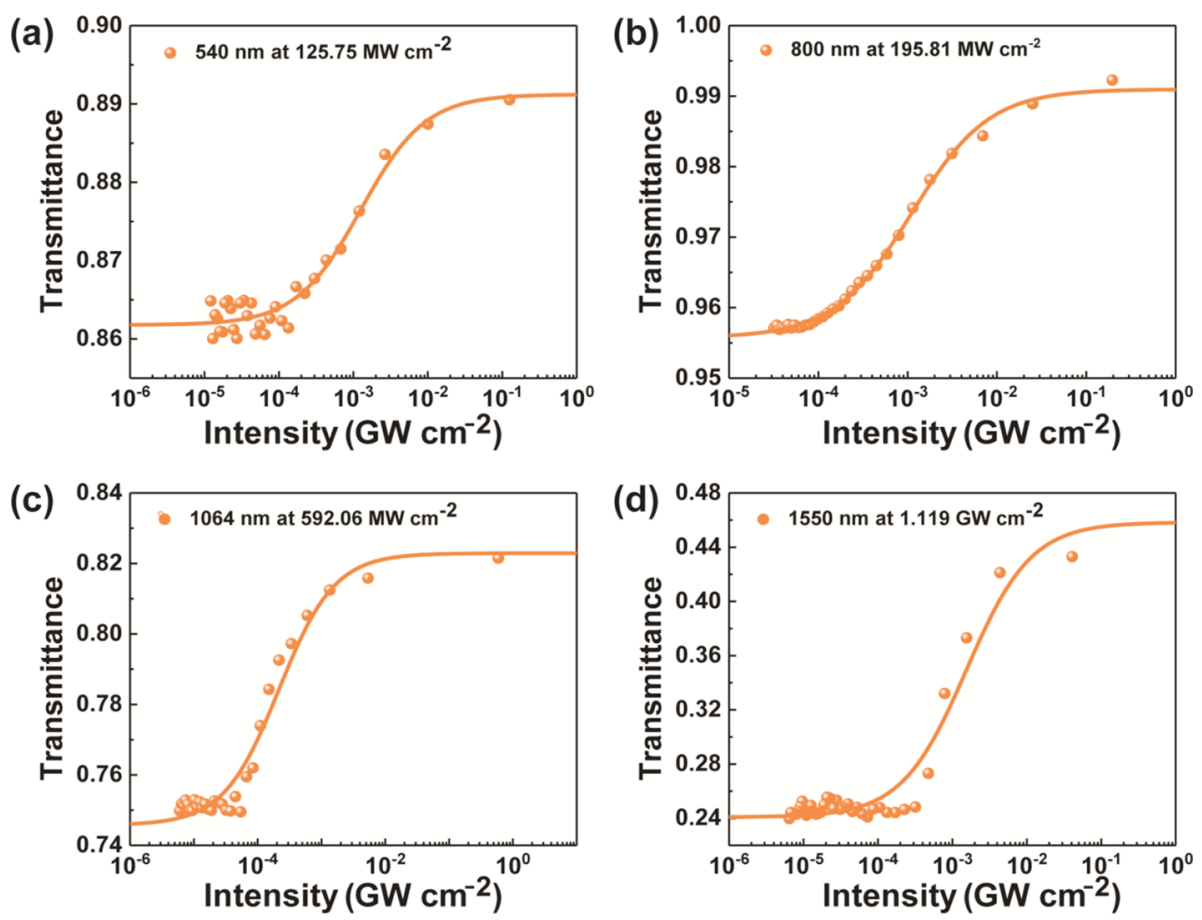

Figure 5. Nonlinear transmittance of fluorinated $\mathrm{Ti}_{3} \mathrm{C}_{2} \mathrm{~T}_{x}$ QDs at wavelengths of 540 (a), 800 (b), 1064 (c), and $1550 \mathrm{~nm}$ (d), respectively.

exhibited a nonlinear increase in transmission as the focal point $(Z=0)$ was approached, with symmetric peaks located at the beam focus, indicating typical saturable absorption over the spectral range from 540 to $1550 \mathrm{~nm}$, which is similar to the results in ref 13 .

The total absorption coefficient $\alpha(I)$ can be expressed as ${ }^{47}$

$$
\alpha(I)=\alpha_{0}+\alpha_{\mathrm{NL}}(I)
$$

where $\alpha_{0}$ and $\alpha_{\mathrm{NL}}(I)$ are the linear and nonlinear absorption coefficients and $I$ is the input laser intensity. Based on a nonlinear theory, ${ }^{47,49}$ the normalized transmission can be presented as

$$
\begin{aligned}
T(z) & =\sum_{m=0}^{\infty}\left(-\alpha_{\mathrm{NL}} I_{0} L_{\mathrm{eff}}\right)^{m} /\left(1+z^{2} / z_{0}^{2}\right)^{m}(m+1)^{3 / 2} \\
& \approx 1-\alpha_{\mathrm{NL}} I_{0} L_{\mathrm{eff}} / 2 \sqrt{2}\left(1+z^{2} / z_{0}^{2}\right)
\end{aligned}
$$

where $z$ is the longitudinal displacement, $I_{0}$ is the on-axis peak intensity, and $\omega_{0}$ and $z_{0}=\pi \omega_{0}{ }^{2} / \lambda$ are the beam waist radius when $Z=0$ and the Rayleigh range for a wavelength of $\lambda$, respectively. $L_{\text {eff }}=\left[1-\exp \left(-\alpha_{0} L\right)\right] /\left(-\alpha_{0} L\right)$ stands for the effective thickness of MXene QDs, where $L$ represents the length of the $\mathrm{Ti}_{3} \mathrm{C}_{2} \mathrm{~T}_{x}$ QDs.

The largest fitted values of $\alpha_{\mathrm{NL}}$ obtained at 540, 800, 1060, and $1550 \mathrm{~nm}$ were $-7.318,-5.581,-4.798$, and $-22.039 \mathrm{~cm}$ $\mathrm{GW}^{-1}$, respectively, which are at least 10 -fold higher than those of the MXene $\mathrm{Ti}_{3} \mathrm{C}_{2} \mathrm{~T}_{x}$ nanosheets reported in ref 13 . Moreover, compared with different kinds of $2 \mathrm{D}$ materials (as listed in Table 1), the obtained absolute value of $\alpha_{\mathrm{NL}}$ in fluorinated $\mathrm{Ti}_{3} \mathrm{C}_{2} \mathrm{~T}_{x}$ QDs is comparable to that of the MXene nanosheets ${ }^{13}$ and is three orders of magnitude larger than those reported for $\mathrm{MoS}_{2}$ nanosheets, ${ }^{50}$ black phosphorus (BP), ${ }^{51}$ BP QDs, ${ }^{52}$ and Se-doped BP nanosheets, ${ }^{49}$ illustrating the stronger interaction between light and fluorinated $\mathrm{Ti}_{3} \mathrm{C}_{2} \mathrm{~T}_{x}$ QDs.

Transmittance can be given by ${ }^{54}$

$$
T(I)=1-\Delta T \times \exp \left(\frac{I}{I_{\text {sat }}}\right)-T_{\mathrm{ns}}
$$

where $\Delta T$ represents the modulation depth of MXene QDs, $I$ $=I_{0} /\left(1+z^{2} / z_{0}^{2}\right)$ is the Gaussian distribution of the incident beam, $I_{\text {sat }}$ stands for saturable intensity, and $T_{\mathrm{ns}}$ is the nonsaturable component.

Figure 5 displays the nonlinear transmission properties as a function of excitation intensity obtained by translating the transmittance curve under the peak intensities of $125.75 \mathrm{MW}$ $\mathrm{cm}^{-2}$ at $540 \mathrm{~nm}, 195.81 \mathrm{MW} \mathrm{cm}^{-2}$ at $800 \mathrm{~nm}, 592.06 \mathrm{MW}$ $\mathrm{cm}^{-2}$ at $1060 \mathrm{~nm}$, and $1.119 \mathrm{GW} \mathrm{cm}^{-2}$ at $1550 \mathrm{~nm}$. By fitting the experimental data, the resulting saturable absorption intensities for 540, 800, 1064, and $1550 \mathrm{~nm}$ were inferred to

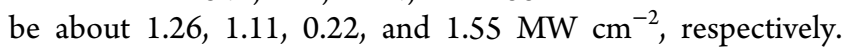
Notably, the saturable absorption intensity was close to that of graphene, $^{53}$ which is much lower than that of other mainstream materials, indicating that the fluorinated $\mathrm{Ti}_{3} \mathrm{C}_{2} \mathrm{~T}_{x}$ QDs are also sensitive to the irradiation intensity and are favorable for use in mode-locking or Q-switching. It is notable that the fluorinated $\mathrm{Ti}_{3} \mathrm{C}_{2} \mathrm{~T}_{x}$ QDs feature the lowest saturable absorption intensity at $1064 \mathrm{~nm}$, which indicates that this material is more favorable for potential low-threshold applications near the band. The saturable absorber features the highest modulation depth of $21.75 \pm 1.14 \%$ at a wavelength of $1550 \mathrm{~nm}$. More importantly, the fluorinated $\mathrm{Ti}_{3} \mathrm{C}_{2} \mathrm{~T}_{x}$ QDs have about three orders of magnitude lower saturable intensity than the MXene $\mathrm{Ti}_{3} \mathrm{C}_{2} \mathrm{~T}_{x}$ nanosheets, while their modulation depths are similar. ${ }^{13}$ Due to the quantum confinement effect of their ultrasmall size, the optical characteristics of the $\mathrm{Ti}_{3} \mathrm{C}_{2} \mathrm{~T}_{x}$ QDs could be correspondingly transformed. Such a lower saturable intensity contributes to reduce noise fluctuations originating from stronger saturation of SA and diminish Q-switching instabilities derived from thermal effects in a laser cavity. ${ }^{55}$ The strong saturable absorption combined with broadband nonlinear response 

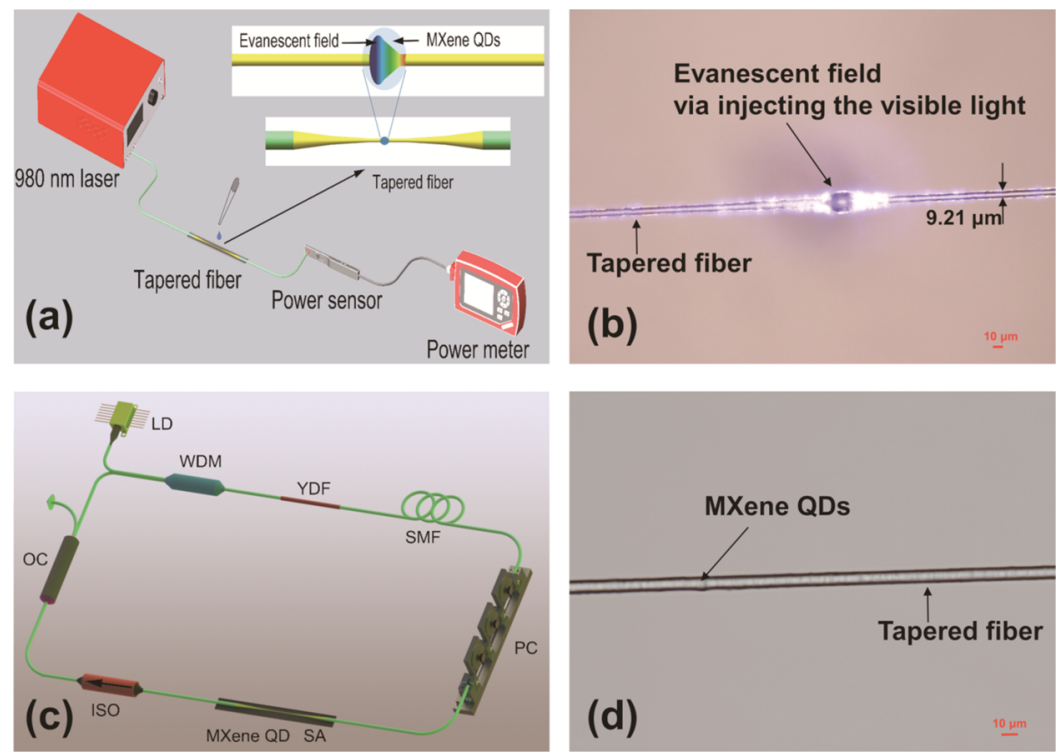

Figure 6. (a) Schematic illustrations of the principle of photo-deposition method. (b) Leaked light appeared in the waist region. (c) Schematic diagram of the laser design. (d) Fluorinated $\mathrm{Ti}_{3} \mathrm{C}_{2} \mathrm{~T}_{x}$ QD saturable absorber device after deposition.
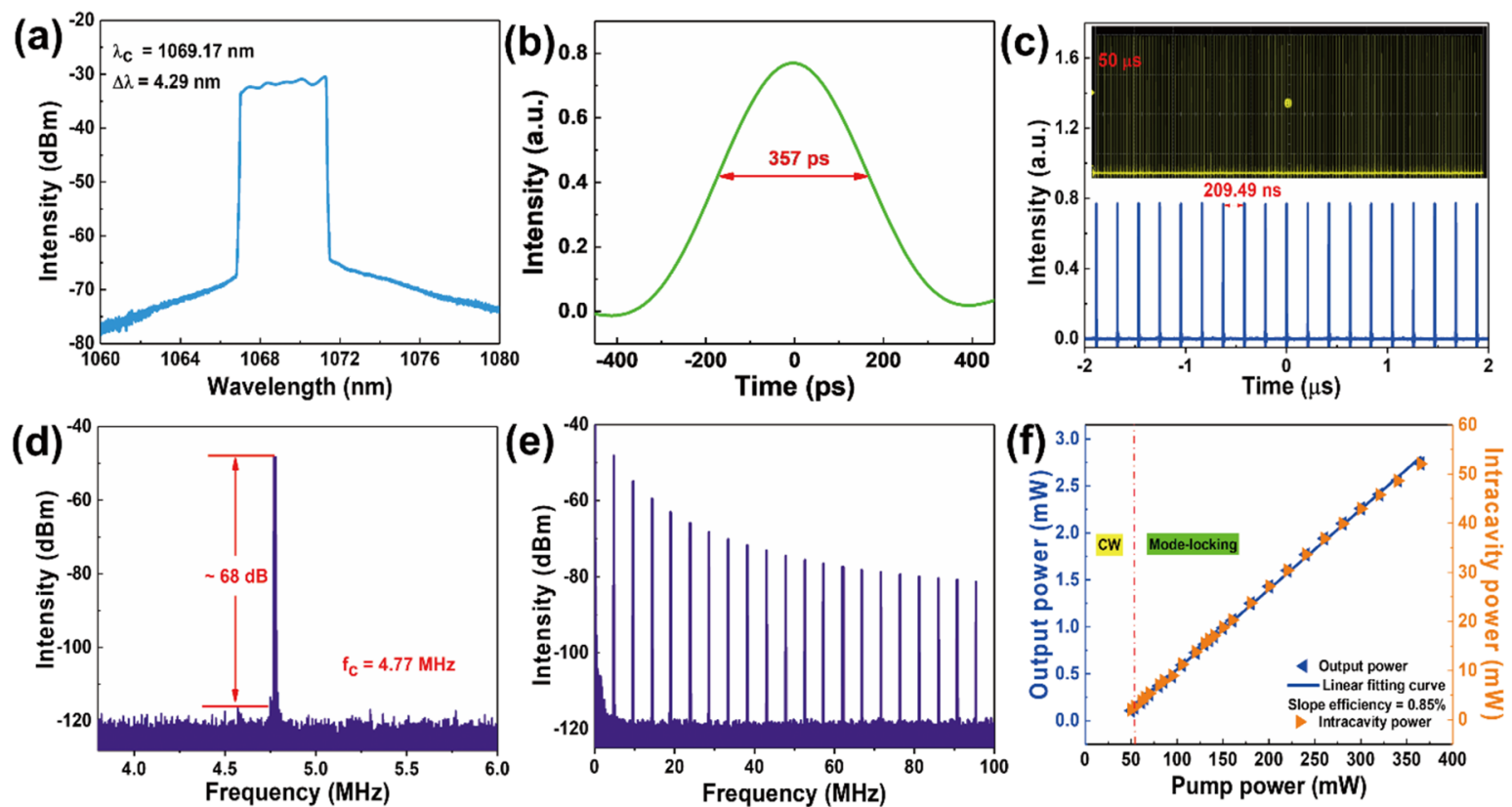

Figure 7. (a) Optical spectrum of dissipative solitons. (b) Single pulse. (c) Output pulse trains within $50 \mu$ s (upper) and $4 \mu$ s (lower). (d) RF spectrum of fundamental frequency. (e) Wideband RF spectrum. (f) Variation of output power and intracavity power as a function of the pump power.

makes $\mathrm{Ti}_{3} \mathrm{C}_{2} \mathrm{~T}_{x}$ QDs a promising material for photonic and optoelectronic devices from the visible to NIR spectral regions.

2.3. Mode-Locking Performance of Fluorinated $\mathrm{Ti}_{3} \mathrm{C}_{2} \mathrm{~T}_{x}$ QD Saturable Absorber. To further verify the saturable absorption properties, fluorinated $\mathrm{Ti}_{3} \mathrm{C}_{2} \mathrm{~T}_{x}$ QDs were used to fabricate the saturable absorber device. Due to the combination of the strong saturable absorption of samples and the long interaction distance of the microfiber, the photodeposition method, has been widely employed to fabricate various types of SA devices ranging from graphene, ${ }^{56}$ TMDs, ${ }^{57}$ $\mathrm{BP},{ }^{58}$ bismuthene, $^{59}$ and antimonene. ${ }^{60}$

A fluorinated $\mathrm{Ti}_{3} \mathrm{C}_{2} \mathrm{~T}_{x} \mathrm{QD}$ dispersion was deposited onto a clear microfiber, where the evanescent light field transmitted outside the fiber core, as illustrated in Figure 6a,b,d. First, the clear microfiber made by the flame taper method (waist diameter: $\sim 9.21 \mu \mathrm{m}$; insertion loss: $0.69 \mathrm{~dB})^{61}$ was incorporated into the cavity (Figure 6c), but there was only continuous wave output under different polarization states of the PC while increasing the pump power. Then, it was connected into the photo-deposition system with a continuous-wave $980 \mathrm{~nm}$ laser as an optical source, as demonstrated in Figure 6a. When the output power was tuned up to $25 \mathrm{~mW}$, which induced light propagation through the evanescent field of the tapered fiber, the leaked light appeared in the waist region within the immersion of the fluorinated $\mathrm{Ti}_{3} \mathrm{C}_{2} \mathrm{~T}_{x}$ QDs dispersion, as shown in Figure $6 \mathrm{~b}$. In this regime, the fluorinated $\mathrm{Ti}_{3} \mathrm{C}_{2} \mathrm{~T}_{x}$ QDs were trapped and collected onto the waist region. Here, the interaction length of this device was 
(a)
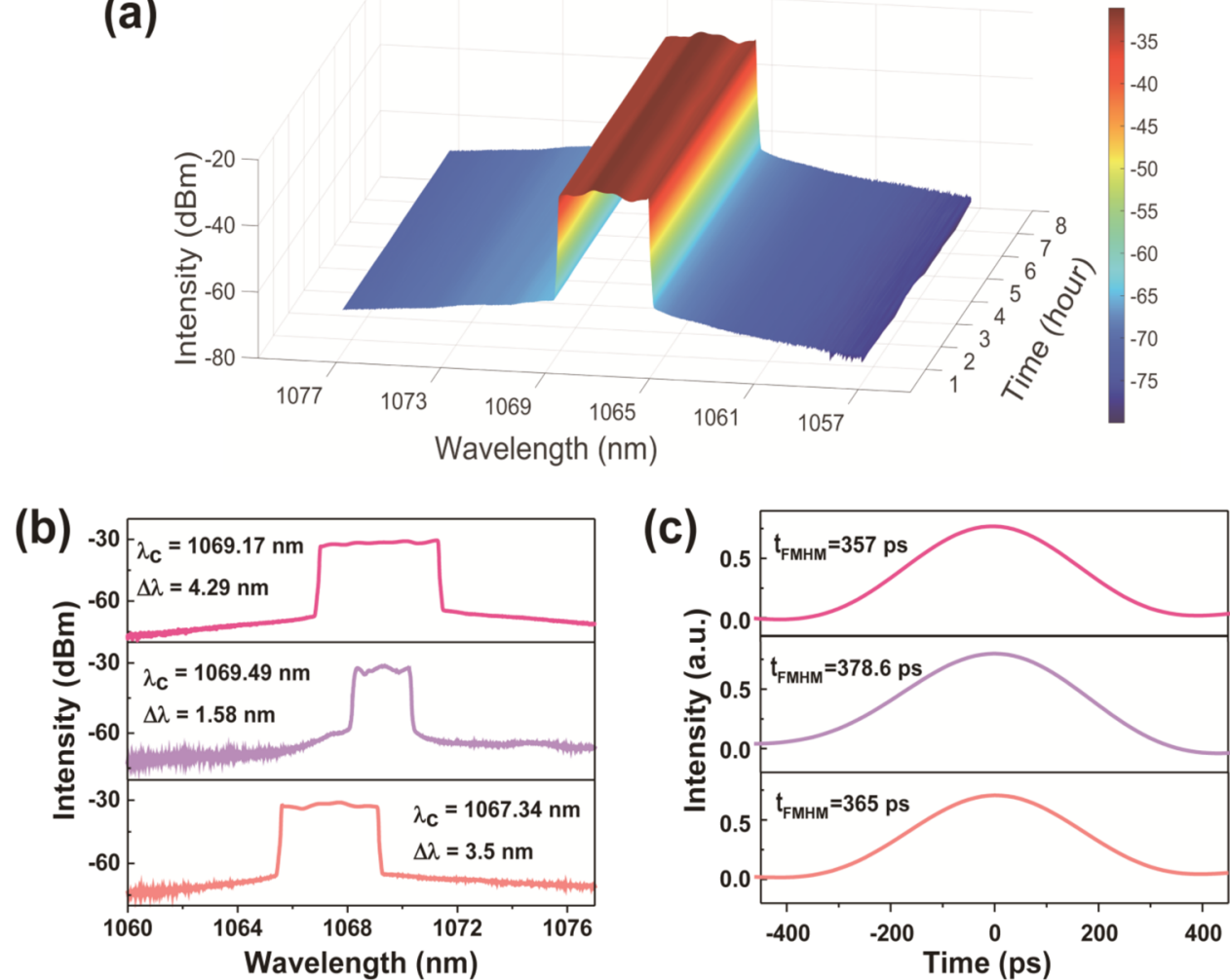

Figure 8. (a) $8 \mathrm{~h}$ stability of the optical spectrum of dissipative soliton. (b) Tunable optical spectrum from 1065.59 to $1071.32 \mathrm{~nm}$. (c) Corresponding output pulse duration.

$\sim 200 \mu \mathrm{m}$. A power meter was followed by the opposite end of the tapered fiber through a power sensor for real-time measurement during the deposition process.

After completing the deposition of the fluorinated $\mathrm{Ti}_{3} \mathrm{C}_{2} \mathrm{~T}_{x}$ QDs (Figure 6d), the measured insertion loss of the fluorinated $\mathrm{Ti}_{3} \mathrm{C}_{2} \mathrm{~T}_{x}$ QD SA was $\sim 1.39 \mathrm{~dB}$. The method of depositing fluorinated $\mathrm{Ti}_{3} \mathrm{C}_{2} \mathrm{~T}_{x}$ QDs onto the microfiber where an evanescent wave coupling in the waist region is formed is conducive to have a strong light-matter interaction and endures high thermal damage. ${ }^{57,62}$ As a result, perpendicular irradiation on the optical material with extra heat introduced can be confined, which contributes significantly to the high optical threshold and air stability of the saturable absorber device.

A fluorinated $\mathrm{Ti}_{3} \mathrm{C}_{2} \mathrm{~T}_{x}$ QD-based saturable absorber device was incorporated into an ytterbium-doped passively modelocked fiber laser. The cavity configuration is depicted schematically (Figure 6d). In this cavity, the gain medium is a $75 \mathrm{~cm}$ Yb-doped fiber (LIEKKI Yb1200-4/125). It was pumped by a $980 \mathrm{~nm}$ laser diode via a 980/1064 nm wavelength division multiplexer (WDM). To realize diverse pulse generation regimes, a $30 \mathrm{~m}$ single mode fiber (SMF, Corning HI 1060) was inserted into the fiber laser to extend the length of the cavity and promote the quality of output pulse. A polarization controller (PC) was employed to tune the polarization state and net cavity birefringence. A polarizationindependent isolator (PI-ISO) was inserted for unidirectional propagation. The pulses of the ring cavity were extracted by the $5 \%$ port of a fiber optical coupler (OC) for output measurements. The total length was $\sim 41.93 \mathrm{~m}$, which corresponds to a net normal dispersion of $\sim 0.92 \mathrm{ps}^{2}$. The output laser operation was monitored using an optical spectrum analyzer, an oscilloscope, and a spectrum analyzer.

After the fluorinated $\mathrm{Ti}_{3} \mathrm{C}_{2} \mathrm{~T}_{x}$ QD SA device was incorporated into the laser cavity, mode-locking operation was successfully achieved at $54 \mathrm{~mW}$ (threshold pump power) by setting the PC properly. As the pump power was further slightly boosted to $61 \mathrm{~mW}$, a stable mode-locking regime was steadily obtained by fine-tuning the PC, as shown in Figure 7. The microfiber provides a long distance for light-matter interaction through the strong evanescent field. In this fiber laser, MXene QDs could absorb the light transmitting through the microfiber and achieve to be saturated, leading to modelocking pulse generation because of saturable absorption effect.

The optical spectrum (Figure 7a) with sharp steep spectral edges suggested the typical characteristics of dissipative solitons in fiber lasers in a YDFL. It was centered at 1069.17 $\mathrm{nm}$ with a $3 \mathrm{~dB}$ bandwidth of $4.29 \mathrm{~nm}$. The pulse width (FWHM) was 357 ps, as shown in Figure 7b. Therefore, the time-bandwidth product was $\sim 401.93$, which indicates that the pulse was heavily chirped, which is also one of the characteristics of dissipative solitons in a YDFL. ${ }^{63}$ The uniform pulse train within $4 \mu \mathrm{s}$ (lower) and $50 \mu \mathrm{s}$ (upper) was recorded, as shown in Figure $7 c$, indicating that pulses without any evident power jitter were developed as a consequence of mode locking in the laser. The time interval between pulses was $209.49 \mathrm{~ns}$, which is consistent with the length of the cavity.

The signal-to-noise-ratio (SNR) was up to $\sim 68 \mathrm{~dB}$ at 4.77 $\mathrm{MHz}$ (fundamental repetition rate), as shown in Figure $7 \mathrm{~d}$. The wideband radio frequency (RF) spectrum without any redundant peak components was also recorded and is shown in Figure $7 \mathrm{e}$, suggesting that the mode-locking pulses demonstrate highly stable performance. The results of our laser cavity 
demonstrate better performance than those reported for $\mathrm{CH}_{3} \mathrm{NH}_{3} \mathrm{PbI}_{3}$ (with a pulse width of 931 ps and an SNR of $53 \mathrm{~dB})^{64}$ and $\alpha-\mathrm{Mo}_{2} \mathrm{C}$ (with a pulse width of $418 \mathrm{ps}$ and an SNR of $64 \mathrm{~dB}) .{ }^{65}$ The variation of the output power as a function of the pump power is plotted in Figure $7 \mathrm{f}$. The relatively low efficiency was ascribed to the high insertion loss of the SA device and the small output ratio of OC. Even though the pulse duration is in the order of ps because the pulses are heavily chirped in such an ytterbium-doped fiber laser, they could be further shortened by a de-chirp technique. ${ }^{55}$ Further research with a low-insertion-loss saturable absorber device could improve this parameter. In the mode-locking regime, the maximum output average power could reach up to $2.74 \mathrm{~mW}$ at a pump power of $365 \mathrm{~mW}$, corresponding to a high intracavity pulse energy of $10.91 \mathrm{~nJ}$, which is higher than that of $\beta$-PbO QDs. ${ }^{48}$ Notably, the threshold of the fluorinated $\mathrm{Ti}_{3} \mathrm{C}_{2} \mathrm{~T}_{x}$ QD SA for mode locking is lower than those of $\mathrm{MoS}_{2}$, ${ }^{57} \mathrm{Bi}_{2} \mathrm{Te}_{3}$, ${ }^{66}$ MXene $\mathrm{Ti}_{3} \mathrm{C}_{2} \mathrm{~T}_{x}$ nanosheets, ${ }^{13} \mathrm{CH}_{3} \mathrm{NH}_{3} \mathrm{PbI}_{3},{ }^{64}$ and bismuthine, ${ }^{67}$ revealing its promising potential for obtaining pulse generation under a lower pump power.

To study the long-term stability of the dissipative soliton, we recorded the optical spectrum every $2 \mathrm{~h}$ for $8 \mathrm{~h}$ under fixed conditions (Figure 8a). It can be seen that there was almost no drift in the central wavelength and no new frequency components appeared over this period, suggesting that the obtained mode-locking state was highly stable. It is noteworthy that the wavelength tunable phenomenon could be observed with the orientation variation of the $\mathrm{PC}$ when the pump power was $116 \mathrm{~mW}$, as presented in Figure $8 \mathrm{~b}, \mathrm{c}$. The center wavelength shifted from 1069.17 to $1069.49 \mathrm{~nm}$ and then to $1067.34 \mathrm{~nm}$, while the $3 \mathrm{~dB}$ bandwidth changed from 4.29 to $1.58 \mathrm{~nm}$ and then to $3.5 \mathrm{~nm}$. The pulse width changed slightly from 357 to 387.6 ps during this period. Furthermore, when the fluorinated $\mathrm{Ti}_{3} \mathrm{C}_{2} \mathrm{~T}_{x}$ QD SA device was removed from the cavity, we could not observe the mode-locking operation under different pump power and polarization states, which further indicates that the mode-locked pulse generation origins from the strong nonlinear absorption of the fluorinated $\mathrm{Ti}_{3} \mathrm{C}_{2} \mathrm{~T}_{x} \mathrm{QD}$ SA.

The saturable absorbers with excellent properties, such as broadband response, low threshold, wavelength tenability, strong nonlinearities, and stability, are expected to be applied in different kinds of industrial applications. The materials could be modified to meet these requirements by improving the quality with efficient synthesis methods or developing different SA devices. As a result, this fluorinated MXene QDs possess low thresholds and strong nonlinearity over a broad range, which covers the bands from visible to NIR spectral regions, thus having the potential to be further developed to some devices in these wavelengths. For example, they can be also used to achieve Q-switching and wavelength tunable photonics devices at a conventional telecommunication band.

\section{CONCLUSIONS}

In summary, we proposed an electrochemical exfoliation method with synchronous fluorination to synthesize $\mathrm{Ti}_{3} \mathrm{C}_{2} \mathrm{~T}_{x}$ MXene QDs with enhanced stability. The presence of oxygenic and hydrophilic termination groups on the surface of MXene QDs could be avoided, which suppresses degradation and contributes to long-term stability. The fluorinated $\mathrm{Ti}_{3} \mathrm{C}_{2} \mathrm{~T}_{x}$ QDs exhibited broadband saturable absorption with lower saturable absorption intensity than some mainstream 2D materials. The MXene QDs could be employed as an effective SA in a YDFL, and stable mode-locked pulses could be extracted at a relatively low threshold power. The tunable optical spectra revealed the lasing wavelength tunability and flexibility of the laser cavity. This work provides a green synthesis strategy for MXene $\mathrm{Ti}_{3} \mathrm{C}_{2} \mathrm{~T}_{x}$ QDs and demonstrates the potential of MXene QDs for novel low-threshold and broadband photonic applications.

\section{EXPERIMENTAL SECTION}

4.1. Electrochemical Exfoliation and Fluorination of $\mathrm{Ti}_{3} \mathrm{C}_{2} \mathrm{~T}_{x}$ MXene QDs. The MXene QDs were prepared in an electrochemical cell system with three electrodes, in which the compact bulk $\mathrm{Ti}_{3} \mathrm{AlC}_{2}$ was for a working electrode, an $\mathrm{Ag}$ wire was used for a quasi-reference electrode, and a Pt wire was for a counterelectrode. $\mathrm{A}$ bulk $\mathrm{Ti}_{3} \mathrm{AlC}_{2}$ (purity: 98\%, Forsman Scientific (Beijing) Co. Ltd.) was cut into small pieces $(\varphi 1 \mathrm{~cm} \times 0.2 \mathrm{~cm})$. To avoid the bulk $\mathrm{Ti}_{3} \mathrm{AlC}_{2}$ falling off during the etching procedure, the anode was fixed by a $\mathrm{Cu}$ clamp and partially inserted into the electrolyte. To prepare the non-aqueous electrolyte, $20 \mathrm{~g}$ of $[\mathrm{EMIM}]\left[\mathrm{PF}_{6}\right](98.0 \%$, Aladdin) was added into $100 \mathrm{~mL}$ of $\mathrm{MeCN}$ (gradient grade, $\geq 99.9 \%, \mathrm{Li}$ Chrosolv). The mixed solution was added into a $150 \mathrm{~mL}$ four-neck flask with three electrodes and a glass pipe inserted. The $[\mathrm{EMIM}]\left[\mathrm{PF}_{6}\right] / \mathrm{MeCN}$ electrolyte was bubbled with $\operatorname{Ar}(\geq 99.999 \%)$ for 5 min before use. A constant potential vs $\mathrm{Ag}$ wire $(3-7 \mathrm{~V})$ was applied. The process had maintained for $5 \mathrm{~h}$, accompanied by electrolytic decomposition of $\mathrm{PF}_{6}{ }^{-}$into $\mathrm{F}^{-}$as well as the selective etching of $\mathrm{Al}$ layer of $\mathrm{Ti}_{3} \mathrm{AlC}_{2}$. After etching, the electrolyte became brown, suspended with $\mathrm{Ti}_{3} \mathrm{C}_{2} \mathrm{~T}_{x}$ powders and fragments. The supernatant was then centrifuged for 30 min at $3500 \mathrm{rpm}$ to separate the large particles from the electrolyte. Furthermore, the suspension was further collected and centrifuged at $7000 \mathrm{rpm}$ for $30 \mathrm{~min}$ to obtain the sediment. The sediment was obtained and then added into $\mathrm{MeCN}$ followed by ultrasonication under $\mathrm{N}_{2}$ for $10 \mathrm{~h}$. The mixer was further centrifuged at $7000 \mathrm{rpm}$ for $30 \mathrm{~min}$ to eliminate the impurity of some large particles, and the supernatant containing the as-prepared $\mathrm{Ti}_{3} \mathrm{C}_{2} \mathrm{~T}_{x}$ MXene QDs was stored at $4{ }^{\circ} \mathrm{C}$ for further use.

4.2. Characterization Methods. An X-ray diffractometer (D8 Advance, Bruker AXS, Germany) with $\mathrm{Cu} \mathrm{K}$ radiation was used to analyze the phase composition of the samples. The patterns were scanned with a step of $0.02^{\circ} 2 \theta$ with a collection time of $1 \mathrm{~s}$ per step. The microstructures and chemical compositions were analyzed by scanning electron microscopy (SEM, QUANTA 250 FEG, FEI, USA) at $20 \mathrm{kV}$. The chemical composition and bonding energy were determined by X-ray photoelectron spectroscopy (XPS, Kratos AXIS ULTRA DLD). The X-ray source is monochromic $\mathrm{Al}(h v=1486.6$ $\mathrm{eV}$ ) with a power of $96 \mathrm{~W}$, and the X-ray spot size was set to $700 \times$ $300 \mathrm{um}$. Transmission electron microscopy and high-resolution TEM images were measured using a Tecnai F20 (FEI, USA, $200 \mathrm{kV}$ ) electron microscope.

4.3. Z-Scan Measurements. A Ti:sapphire oscillator centered at $800 \mathrm{~nm}$ with a pulse width of $100 \mathrm{fs}$ and an optical parametric amplifier system was utilized as the incident laser source. ${ }^{48}$ The beam waist was estimated to be $22.5 \mu \mathrm{m}$ for $540 \mathrm{~nm}, 25.5 \mu \mathrm{m}$ for $800 \mathrm{~nm}$, $12.7 \mu \mathrm{m}$ for $1064 \mathrm{~nm}$, and $18.5 \mu \mathrm{m}$ for $1550 \mathrm{~nm}$. The fluorinated $\mathrm{Ti}_{3} \mathrm{C}_{2} \mathrm{~T}_{x}$ QDs dispersed in acetonitrile were held in a $1 \mathrm{~mm}$ cuvette.

\section{ASSOCIATED CONTENT}

\section{(s) Supporting Information}

The Supporting Information is available free of charge at https://pubs.acs.org/doi/10.1021/acsanm.0c02369.

Synthesis method for $\mathrm{Ti}_{3} \mathrm{C}_{2} \mathrm{~T}_{x}$ MXene QDs by HF etching, electrochemical etching and fluorination mechanism, CV test, AFM and FTIR results and the stability of MXene QDs, high-resolution XPS of aluminum (PDF) 


\section{AUTHOR INFORMATION}

\section{Corresponding Authors}

Shixiang Xu - College of Physics and Optoelectronic Engineering, Shenzhen University, Shenzhen 518060, China; Email:shxxu@szu.edu.cn

Sanshui Xiao - DTU Fotonik, Department of Photonics Engineering, Technical University of Denmark, Lyngby 2800, Denmark; @ orcid.org/0000-0001-6529-5047; Email: saxi@fotonik.dtu.dk

\section{Authors}

Fumei Yang - College of Physics and Optoelectronic Engineering, Shenzhen University, Shenzhen 518060, China; ๑ orcid.org/0000-0002-3427-3731

Yanqi Ge - College of Physics and Optoelectronic Engineering, Shenzhen University, Shenzhen 518060, China; DTU Fotonik, Department of Photonics Engineering, Technical University of Denmark, Lyngby 2800, Denmark; - orcid.org/0000-0003-1627-2951

Teng Yin - College of Physics and Optoelectronic Engineering, Shenzhen University, Shenzhen 518060, China

Jia Guo - College of Physics and Optoelectronic Engineering, Shenzhen University, Shenzhen 518060, China

Feng Zhang - College of Physics and Optoelectronic Engineering, Shenzhen University, Shenzhen 518060, China

Xian Tang - College of Physics and Optoelectronic Engineering, Shenzhen University, Shenzhen 518060, China

Meng Qiu - College of Physics and Optoelectronic Engineering, Shenzhen University, Shenzhen 518060, China

Weiyuan Liang - College of Physics and Optoelectronic Engineering, Shenzhen University, Shenzhen 518060, China

Ning Xu - College of Physics and Optoelectronic Engineering, Shenzhen University, Shenzhen 518060, China

Cong Wang - College of Physics and Optoelectronic Engineering, Shenzhen University, Shenzhen 518060, China

Yufeng Song - College of Physics and Optoelectronic

Engineering, Shenzhen University, Shenzhen 518060, China

Complete contact information is available at:

https://pubs.acs.org/10.1021/acsanm.0c02369

\section{Author Contributions}

${ }^{\ddagger}$ F.Y., Y.G., and T.Y. contributed equally to this work. The manuscript was written through contributions of all authors. All authors have given approval to the final version of the manuscript.

\section{Notes}

The authors declare no competing financial interest.

\section{ACKNOWLEDGMENTS}

F.Y. received funding from the Shenzhen Basic Research Project on Subject Layout (JCYJ20170412105812811) and the Postgraduate Innovation Development Fund Project of Shenzhen University (PIDFPZR2019011). T.Y., J.G., F.Z., X.T., M.Q., W.L., N.X., C.W., and Y. S. received funding from the National Science Foundation of China (nos. 61775142, 12004089, and 61905149). Y.G. received funding from the Natural Science Foundation of Guangdong Province (2019A1515011415) and the International Network Program (no. 7059-00104B). The authors thank Prof. Han Zhang for helpful supervision. The authors gratefully acknowledge the Materials and Devices Testing Center of Graduate School at Shenzhen, Tsinghua University. Authors also acknowledge the support from Instrumental Analysis Center of Shenzhen University (Xili Campus).

\section{REFERENCES}

(1) Naguib, M.; Kurtoglu, M.; Presser, V.; Lu, J.; Niu, J.; Heon, M.; Hultman, L.; Gogotsi, Y.; Barsoum, M. W. Two-Dimensional Nanocrystals Produced by Exfoliation of $\mathrm{Ti}_{3} \mathrm{AlC}_{2}$. Adv. Mater. 2011, 23, 4248-4253.

(2) Anasori, B.; Lukatskaya, M. R.; Gogotsi, Y. 2D Metal Carbides and Nitrides (MXenes) for Energy Storage. Nat. Rev. Mater. 2017, 2, 16098

(3) Dillon, A. D.; Ghidiu, M. J.; Krick, A. L.; Griggs, J.; May, S. J.; Gogotsi, Y.; Barsoum, M. W.; Fafarman, A. T. Highly Conductive Optical Quality Solution-Processed Films of 2D Titanium Carbide. Adv. Funct. Mater. 2016, 26, 4162-4168.

(4) Sang, X.; Xie, Y.; Lin, M. W.; Alhabeb, M.; Van Aken, K. L.; Gogotsi, Y.; Kent, P. R. C.; Xiao, K.; Unocic, R. R. Atomic Defects in Monolayer Titanium Carbide $\left(\mathrm{Ti}_{3} \mathrm{C}_{2} \mathrm{~T}_{x}\right)$ MXene. ACS Nano 2016, 10, 9193-9200

(5) Shahzad, F.; Alhabeb, M.; Hatter, C. B.; Anasori, B.; Man Hong, S.; Koo, C. M.; Gogotsi, Y. Electromagnetic Interference Shielding with 2D Transition Metal Carbides (MXenes). Science 2016, 353, 1137.

(6) Jiang, X.; Kuklin, A. V.; Baev, A.; Ge, Y.; Ågren, H.; Zhang, H.; Prasad, P. N. Two-Dimensional MXenes: From Morphological to Optical, Electric, and Magnetic Properties and Applications. Phys. Rep. 2020, 848, 1-58.

(7) Khazaei, M.; Arai, M.; Sasaki, T.; Estili, M.; Sakka, Y. TwoDimensional Molybdenum Carbides: Potential Thermoelectric Materials of the MXene Family. Phys. Chem. Chem. Phys. 2014, 16, 7841-7849.

(8) Mashtalir, O.; Lukatskaya, M. R.; Zhao, M. Q.; Barsoum, M. W.; Gogotsi, Y. Amine-Assisted Delamination of $\mathrm{Nb}_{2} \mathrm{C}$ MXene for Li-Ion Energy Storage Devices. Adv. Mater. 2015, 27, 3501-3506.

(9) Ma, Y.; Liu, N.; Li, L.; Hu, X.; Zou, Z.; Wang, J.; Luo, S.; Gao, Y. A Highly Flexible and Sensitive Piezoresistive Sensor based on MXene with Greatly Changed Interlayer Distances. Nat. Commun. 2017, 8, 1207.

(10) Kim, S. J.; Koh, H.-J.; Ren, C. E.; Kwon, O.; Maleski, K.; Cho, S.-Y.; Anasori, B.; Kim, C.-K.; Choi, Y.-K.; Kim, J.; Gogotsi, Y.; Jung, H.-T. Metallic $\mathrm{Ti}_{3} \mathrm{C}_{2} \mathrm{~T}_{x}$ MXene Gas Sensors with Ultrahigh Signal-toNoise Ratio. ACS Nano 2018, 12, 986-993.

(11) Gao, G.; O’Mullane, A. P.; Du, A. 2D MXenes: A New Family of Promising Catalysts for the Hydrogen Evolution Reaction. ACS Catal. 2016, 7, 494-500.

(12) Zhang, J.; Zhao, Y.; Guo, X.; Chen, C.; Dong, C.-L.; Liu, R.-S.; Han, C.-P.; Li, Y.; Gogotsi, Y.; Wang, G. Single Platinum Atoms Immobilized on an MXene as an Efficient Catalyst for the Hydrogen Evolution Reaction. Nat. Catal. 2018, 1, 985-992.

(13) Jiang, X.; Liu, S.; Liang, W.; Luo, S.; He, Z.; Ge, Y.; Wang, H.; Cao, R.; Zhang, F.; Wen, Q.; Li, J.; Bao, Q.; Fan, D.; Zhang, H. Broadband Nonlinear Photonics in Few-Layer MXene $\mathrm{Ti}_{3} \mathrm{C}_{2} \mathrm{~T}_{\mathrm{x}}(\mathrm{T}=$ F, O, or OH). Laser Photonics Rev. 2017, 12, 1700229.

(14) Jhon, Y. I.; Koo, J.; Anasori, B.; Seo, M.; Lee, J. H.; Gogotsi, Y.; Jhon, Y. M. Metallic MXene Saturable Absorber for Femtosecond Mode-Locked Lasers. Adv. Mater. 2017, 29, 1702496.

(15) Shao, B.; Liu, Z.; Zeng, G.; Wang, H.; Liang, Q.; He, Q.; Cheng, M.; Zhou, C.; Jiang, L.; Song, B. Two-Dimensional Transition Metal Carbide and Nitride (MXene) Derived Quantum Dots (QDs): Synthesis, Properties, Applications and Prospects. J. Mater. Chem. A 2020, 8, 7508-7535.

(16) Yu, X.; Cai, X.; Cui, H.; Lee, S.-W.; Yu, X.-F.; Liu, B. Fluorinefree Preparation of Titanium Carbide MXene Quantum Dots with High Near-infrared Photothermal Performances for Cancer Therapy. Nanoscale 2017, 9, 17859-17864.

(17) Zeng, Z.; Yan, Y.; Chen, J.; Zan, P.; Tian, Q.; Chen, P. Boosting the Photocatalytic Ability of $\mathrm{Cu}_{2} \mathrm{O}$ Nanowires for $\mathrm{CO}_{2}$ Conversion by MXene Quantum Dots. Adv. Funct. Mater. 2019, 29, 1806500. 
(18) Xu, Q.; Ding, L.; Wen, Y.; Yang, W.; Zhou, H.; Chen, X.; Street, J.; Zhou, A.; Ong, W.-J.; Li, N. High Photoluminescence Quantum Yield of $18.7 \%$ by Using Nitrogen-doped $\mathrm{Ti}_{3} \mathrm{C}_{2}$ MXene Quantum Dots. J. Mater. Chem. C 2018, 6, 6360-6369.

(19) Dall'Agnese, Y.; Lukatskaya, M. R.; Cook, K. M.; Taberna, P.L.; Gogotsi, Y.; Simon, P. High Capacitance of Surface-modified 2D Titanium Carbide in Acidic Electrolyte. Electrochem. Commun. 2014, $48,118-122$.

(20) Halim, J.; Lukatskaya, M. R.; Cook, K. M.; Lu, J.; Smith, C. R.; Näslund, L. A.; May, S. J.; Hultman, L.; Gogotsi, Y.; Eklund, P.; Barsoum, M. W. Transparent Conductive Two-Dimensional Titanium Carbide Epitaxial Thin Films. Chem. Mater. 2014, 26, 2374-2381.

(21) Ghidiu, M.; Naguib, M.; Shi, C.; Mashtalir, O.; Pan, L. M.; Zhang, B.; Yang, J.; Gogotsi, Y.; Billinge, S. J. L.; Barsoum, M. W. Synthesis and Characterization of Two-Dimensional $\mathrm{Nb}_{4} \mathrm{C}_{3}$ (MXene). Chem. Commun. 2014, 50, 9517-9520.

(22) Zhang, C. J.; Pinilla, S.; McEvoy, N.; Cullen, C. P.; Anasori, B.; Long, E.; Park, S.-H.; Seral-Ascaso, A.; Shmeliov, A.; Krishnan, D.; Morant, C.; Liu, X.; Duesberg, G. S.; Gogotsi, Y.; Nicolosi, V. Oxidation Stability of Colloidal Two-Dimensional Titanium Carbides (MXenes). Chem. Mater. 2017, 29, 4848-4856.

(23) Ghidiu, M.; Halim, J.; Kota, S.; Bish, D.; Gogotsi, Y.; Barsoum, M. W. Ion-Exchange and Cation Solvation Reactions in $\mathrm{Ti}_{3} \mathrm{C}_{2}$ MXene. Chem. Mater. 2016, 28, 3507-3514.

(24) Li, M.; Lu, J.; Luo, K.; Li, Y.; Chang, K.; Chen, K.; Zhou, J.; Rosen, J.; Hultman, L.; Eklund, P.; Persson, P. O. Å.; Du, S.; Chai, Z.; Huang, Z.; Huang, Q. Element Replacement Approach by Reaction with Lewis Acidic Molten Salts to Synthesize Nanolaminated MAX Phases and MXenes. J. Am. Chem. Soc. 2019, 141, 4730-4737.

(25) Kamysbayev, V.; Filatov, A. S.; Hu, H.; Rui, X.; Lagunas, F.; Wang, D.; Klie, R. F.; Talapin, D. V. Covalent Surface Modifications and Superconductivity of Two-Dimensional Metal Carbide MXenes. Science 2020, 369, 979-983.

(26) Xu, C.; Wang, L.; Liu, Z.; Chen, L.; Guo, J.; Kang, N.; Ma, X.L.; Cheng, H.-M.; Ren, W. Large-area High-quality 2D Ultrathin $\mathrm{Mo}_{2} \mathrm{C}$ Superconducting Crystals. Nat. Mater. 2015, 14, 1135-1141.

(27) Li, T.; Yao, L.; Liu, Q.; Gu, J.; Luo, R.; Li, J.; Yan, X.; Wang, W.; Liu, P.; Chen, B.; Zhang, W.; Abbas, W.; Naz, R.; Zhang, D. Fluorine-Free Synthesis of High-Purity $\mathrm{Ti}_{3} \mathrm{C}_{2} \mathrm{~T}_{x}(\mathrm{~T}=\mathrm{OH}, \mathrm{O})$ via Alkali Treatment. Angew. Chem., Int. Ed. 2018, 57, 6115-6119.

(28) Yang, S.; Zhang, P.; Wang, F.; Ricciardulli, A. G.; Lohe, M. R.; Blom, P. W. M.; Feng, X. Fluoride-Free Synthesis of TwoDimensional Titanium Carbide (MXene) Using A Binary Aqueous System. Am. Ethnol. 2018, 130, 15717-15721.

(29) Tang, X.; Chen, H.; Ponraj, J. S.; Dhanabalan, S. C.; Xiao, Q.; Fan, D.; Zhang, H. Fluorination-Enhanced Ambient Stability and Electronic Tolerance of Black Phosphorus Quantum Dots. Adv. Sci. 2018, 5, 1800420.

(30) Zu, Y.; Zhang, C.; Guo, X.; Liang, W.; Liu, J.; Su, L.; Zhang, H. A Solid-state Passively Q-switched Tm, Gd:CaF 2 Laser with a $\mathrm{Ti}_{3} \mathrm{C}_{2} \mathrm{~T}_{x}$ MXene Absorber Near $2 \mu \mathrm{m}$. Laser Phys. Lett. 2018, 16, No. 015803 .

(31) Wu, Q.; Jin, X.; Chen, S.; Jiang, X.; Hu, Y.; Jiang, Q.; Wu, L.; Li, J.; Zheng, Z.; Zhang, M.; Zhang, H. MXene-based Saturable Absorber for Femtosecond Mode-locked Fiber Lasers. Opt. Express 2019, 27, 10159-10170.

(32) Yang, Q.; Zhang, F.; Zhang, N.; Zhang, H. Few-layer MXene $\mathrm{Ti}_{3} \mathrm{C}_{2} \mathrm{~T}_{\mathrm{x}}(\mathrm{T}=\mathrm{F}, \mathrm{O}$, or $\mathrm{OH})$ Saturable Absorber for Visible Bulk Laser. Opt. Mater. Express 2019, 9, 1795-1802.

(33) Feng, J.; Li, X.; Feng, T.; Wang, Y.; Liu, J.; Zhang, H. Harmonic Mode-Locked Er-Doped Fiber Laser by Evanescent Field-Based MXene $\mathrm{Ti}_{3} \mathrm{C}_{2} \mathrm{~T}_{\mathrm{x}}(\mathrm{T}=\mathrm{F}, \mathrm{O}$, or $\mathrm{OH})$ Saturable Absorber. Ann. Phys. 2020, 532, 1900437.

(34) Yoon, Y.; Le, T. A.; Tiwari, A. P.; Kim, I.; Barsoum, M. W.; Lee, H. Low Temperature Solution Synthesis of Reduced Two Dimensional $\mathrm{Ti}_{3} \mathrm{C}_{2}$ MXenes with Paramagnetic Behaviour. Nanoscale 2018, 10, 22429-22438.

(35) Peng, C.; Wei, P.; Chen, X.; Zhang, Y.; Zhu, F.; Cao, Y.; Wang, H.; Yu, H.; Peng, F. A Hydrothermal Etching Route to Synthesis of
2D MXene $\left(\mathrm{Ti}_{3} \mathrm{C}_{2}, \mathrm{Nb}_{2} \mathrm{C}\right)$ : Enhanced Exfoliation and Improved Adsorption Performance. Ceram. Int. 2018, 44, 18886-18893.

(36) Mashtalir, O.; Naguib, M.; Mochalin, V. N.; Dall'Agnese, Y.; Heon, M.; Barsoum, M. W.; Gogotsi, Y. Intercalation and Delamination of Layered Carbides and Carbonitrides. Nat. Commun. 2013, 4, 1716.

(37) Ghidiu, M.; Lukatskaya, M. R.; Zhao, M.-Q.; Gogotsi, Y.; Barsoum, M. W. Conductive Two-Dimensional Titanium Carbide 'Clay' with High Volumetric Capacitance. Nature 2014, 516, 78-81.

(38) Li, R.; Zhang, L.; Shi, L.; Wang, P. MXene $\mathrm{Ti}_{3} \mathrm{C}_{2}$ : An Effective 2D Light-to-Heat Conversion Material. ACS Nano 2017, 11, 37523759.

(39) Xuan, J.; Wang, Z.; Chen, Y.; Liang, D.; Cheng, L.; Yang, X.; Liu, Z.; Ma, R.; Sasaki, T.; Geng, F. Organic-Base-Driven Intercalation and Delamination for the Production of Functionalized Titanium Carbide Nanosheets with Superior Photothermal Therapeutic Performance. Angew.Chem. Int. Ed. 2016, 55, 14569-14574.

(40) Karlsson, L. H.; Birch, J.; Halim, J.; Barsoum, M. W.; Persson, P. O. Atomically Resolved Structural and Chemical Investigation of Single MXene Sheets. Nano Lett. 2015, 15, 4955-4960.

(41) Xing, M.; Zhang, J.; Qiu, B.; Tian, B.; Anpo, M.; Che, M. A Brown Mesoporous $\mathrm{TiO}_{2-\mathrm{x}} / \mathrm{MCF}$ Composite with an Extremely High Quantum Yield of Solar Energy Photocatalysis for $\mathrm{H}_{2}$ Evolution. Small 2015, 11, 1920-1929.

(42) Touhara, H.; Okino, F. Property Control of Carbon Materials by Fluorination. Carbon 2000, 38, 241-267.

(43) Wang, L.; Zhang, H.; Wang, B.; Shen, C.; Zhang, C.; Hu, Q.; Zhou, A.; Liu, B. Synthesis and Electrochemical Performance of $\mathrm{Ti}_{3} \mathrm{C}_{2} \mathrm{~T}_{\mathrm{x}}$ with Hydrothermal Process. Electron. Mater. Lett. 2016, 12, 702-710.

(44) Powell, J. M.; Adcock, J.; Dai, S.; Veith, G. M.; Bridges, C. A. Role of Precursor Chemistry in the Direct Fluorination to Form Titanium Based Conversion Anodes for Lithium Ion Batteries. RSC Adv. 2015, 5, 88876-88885.

(45) Xue, Q.; Zhang, H.; Zhu, M.; Pei, Z.; Li, H.; Wang, Z.; Huang, Y.; Huang, Y.; Deng, Q.; Zhou, J.; Du, S.; Huang, Q.; Zhi, C. Photoluminescent $\mathrm{Ti}_{3} \mathrm{C}_{2}$ MXene Quantum Dots for Multicolor Cellular Imaging. Adv. Mater. 2017, 29, 1604847.

(46) Guan, Q.; Ma, J.; Yang, W.; Zhang, R.; Zhang, X.; Dong, X.; Fan, Y.; Cai, L.; Cao, Y.; Zhang, Y.; Li, N.; Xu, Q. Highly Fluorescent $\mathrm{Ti}_{3} \mathrm{C}_{2}$ MXene Quantum Dots for Macrophage Labeling and $\mathrm{Cu}^{2+}$ Ion Sensing. Nanoscale 2019, 11, 14123-14133.

(47) Sheik-Bahae, M.; Said, A. A.; Wei, T. H.; Hagan, D. J.; Van Stryland, E. W. Sensitive Measurement of Optical Nonlinearities Using a Single Beam. IEEE J. Quantum Electron. 1990, 26, 760-769.

(48) Ge, Y.; Huang, W.; Yang, F.; Liu, J.; Wang, C.; Wang, Y.; Guo, J.; Zhang, F.; Song, Y.; Xu, S.; Fan, D.; Zhang, H. Beta-lead Oxide Quantum Dot ( $\beta$-PbO QD) / Polystyrene (PS) Composite Films and Their Applications in Ultrafast Photonics. Nanoscale 2019, 11, 68286837.

(49) Ge, Y.; Chen, S.; Xu, Y.; He, Z.; Liang, Z.; Chen, Y.; Song, Y.; Fan, D.; Zhang, K.; Zhang, H. Few-layer Selenium-doped Black Phosphorus: Synthesis, Nonlinear Optical Properties and Ultrafast Photonics Applications. J. Mater. Chem. C 2017, 5, 6129-6135.

(50) Wang, K.; Wang, J.; Fan, J.; Lotya, M.; O’Neill, A.; Fox, D.; Feng, Y.; Zhang, X.; Jiang, B.; Zhao, Q.; Zhang, H.; Coleman, J. N.; Zhang, L.; Blau, W. J. Ultrafast Saturable Absorption of TwoDimensional $\mathrm{MoS}_{2}$ Nanosheets. ACS Nano 2013, 7, 9260-9267.

(51) Lu, S. B.; Miao, L. L.; Guo, Z. N.; Qi, X.; Zhao, C. J.; Zhang, H.; Wen, S. C.; Tang, D. Y.; Fan, D. Y. Broadband Nonlinear Optical Response in Multi-layer Black Phosphorus: an Emerging Infrared and Mid-infrared Optical Material. Opt. Express 2015, 23, 11183-11194.

(52) Xu, Y.; Wang, Z.; Guo, Z.; Huang, H.; Xiao, Q.; Zhang, H.; Yu, X.-F. Solvothermal Synthesis and Ultrafast Photonics of Black Phosphorus Quantum Dots. Adv. Opt. Mater. 2016, 4, 1223-1229.

(53) Bao, Q.; Zhang, H.; Wang, Y.; Ni, Z.; Yan, Y.; Shen, Z.; Loh, K.; Tang, D. Atomic-Layer Graphene as a Saturable Absorber for Ultrafast Pulsed Lasers. Adv. Opt. Mater. 2009, 19, 3077-3083. 
(54) Zhu, C.; Wang, F.; Meng, Y.; Yuan, X.; Xiu, F.; Luo, H.; Wang, Y.; Li, J.; Lv, X.; He, L.; Xu, Y.; Liu, J.; Zhang, C.; Shi, Y.; Zhang, R.; Zhu, S. A Robust and Tuneable Mid-infrared Optical Switch Enabled by Bulk Dirac Fermions. Nat. Commun. 2017, 8, 14111.

(55) Keller, U. Recent Developments in Compact Ultrafast Lasers. Nature 2003, 424, 831-838.

(56) Song, Y.-W.; Jang, S.-Y.; Han, W.-S.; Bae, M.-K. Graphene Mode-lockers for Fiber Lasers Functioned with Evanescent Field Interaction. Appl. Phys. Lett. 2010, 96, No. 051122.

(57) Du, J.; Wang, Q.; Jiang, G.; Xu, C.; Zhao, C.; Xiang, Y.; Chen, Y.; Wen, S.; Zhang, H. Ytterbium-doped Fiber Laser Passively Mode Locked by Few-layer Molybdenum Disulfide $\left(\mathrm{MoS}_{2}\right)$ Saturable Absorber Functioned with Evanescent Field Interaction. Sci. Rep. 2014, 4, 6346.

(58) Luo, Z.-C.; Liu, M.; Guo, Z.-N.; Jiang, X.-F.; Luo, A.-P.; Zhao, C.-J.; Yu, X.-F.; Xu, W.-C.; Zhang, H. Microfiber-based Few-layer Black Phosphorus Saturable Absorber for Ultra-fast Fiber Laser. Opt. Express 2015, 23, 20030-20039.

(59) Guo, B.; Wang, S.-H.; Wu, Z.-X.; Wang, Z.-X.; Wang, D.-H.; Huang, H.; Zhang, F.; Ge, Y.-Q.; Zhang, H. Sub-200 fs Soliton Modelocked Fiber Laser Based on Bismuthene Saturable Absorber. Opt. Express 2018, 26, 22750-22760.

(60) Song, Y.; Liang, Z.; Jiang, X.; Chen, Y.; Li, Z.; Lu, L.; Ge, Y.; Wang, K.; Zheng, J.; Lu, S. Few-layer Antimonene Decorated Microfiber: Ultra-short Pulse Generation and All-optical Thresholding with Enhanced Long Term Stability. 2D Mater. 2017, 4, No. 045010.

(61) Tong, L.; Zi, F.; Guo, X.; Lou, J. Optical Microfibers and Nanofibers: A Tutorial. Opt. Commun. 2012, 285, 4641-4647.

(62) Raichlin, Y.; Fel, L.; Katzir, A. Evanescent-wave Infrared Spectroscopy with Flattened Fibers as Sensing Elements. Opt. Lett. 2003, 28, 2297-2299.

(63) Grelu, P.; Akhmediev, N. Dissipative Solitons for Mode-locked Lasers. Nat. Photonics 2012, 6, 84-92.

(64) Li, P.; Chen, Y.; Yang, T.; Wang, Z.; Lin, H.; Xu, Y.; Li, L.; Mu, H.; Shivananju, B. N.; Zhang, Y.; Zhang, Q.; Pan, A.; Li, S.; Tang, D.; Jia, B.; Zhang, H.; Bao, Q. Two-Dimensional $\mathrm{CH}_{3} \mathrm{NH}_{3} \mathrm{PbI}_{3}$ Perovskite Nanosheets for Ultrafast Pulsed Fiber Lasers. ACS Appl. Mater. Interfaces 2017, 9, 12759-12765.

(65) Tuo, M.; Xu, C.; Mu, H.; Bao, X.; Wang, Y.; Xiao, S.; Ma, W.; Li, L.; Tang, D.; Zhang, H.; Premaratne, M.; Sun, B.; Cheng, H.-M.; Li, S.; Ren, W.; Bao, Q. Ultrathin 2D Transition Metal Carbides for Ultrafast Pulsed Fiber Lasers. ACS Photonics 2018, 5, 1808-1816.

(66) Li, L.; Wang, Y.; Sun, H.; Duan, L.; Wang, X.; Si, J. All-normal Dispersion Passively Mode-locked Yb-doped Fiber Laser With $\mathrm{Bi}_{2} \mathrm{Te}_{3}$ Absorber. Opt. Eng. 2015, 54, No. 046101.

(67) Chai, T.; Li, X.; Feng, T.; Guo, P.; Song, Y.; Chen, Y.; Zhang, H. Few-layer Bismuthene for Ultrashort Pulse Generation in a Dissipative System Based on an Evanescent Field. Nanoscale 2018, 10, 17617-17622. 